\title{
BMJ Open Prescription opioid injection and risk of hepatitis $C$ in relation to traditional drugs of misuse in a prospective cohort of street youth
}

\author{
Scott E Hadland, ${ }^{1,2}$ Kora DeBeck, ${ }^{3,4}$ Thomas Kerr, ${ }^{3,5}$ Cindy Feng, ${ }^{3,6}$ \\ Julio S Montaner, ${ }^{3,5}$ Evan Wood $^{3,5}$
}

To cite: Hadland SE, DeBeck K, Kerr T, et al. Prescription opioid injection and risk of hepatitis $C$ in relation to traditional drugs of misuse in a prospective cohort of street youth. BMJ Open 2014;4:e005419. doi:10.1136/bmjopen-2014005419

- Prepublication history for this paper is available online. To view these files please visit the journal online (http://dx.doi.org/10.1136/ bmjopen-2014-005419).

Received 7 April 2014 Revised 17 June 2014 Accepted 30 June 2014

CrossMark

For numbered affiliations see end of article.

Correspondence to Dr Evan Wood; uhri-ew@cfenet.ubc.ca

\section{ABSTRACT}

Objective: Despite dramatic increases in the misuse of prescription opioids, the extent to which their intravenous injection places drug users at risk of acquiring hepatitis $\mathrm{C}$ virus (HCV) remains unclear. We sought to compare risk of HCV acquisition from injection of prescription opioids to that from other street drugs among high-risk street youth.

Design: Prospective cohort study.

Setting: Vancouver, British Columbia, Canada from September 2005 to November 2011.

Participants: The At-Risk Youth Study (ARYS) is a prospective cohort of drug-using adolescents and young adults aged $14-26$ years. Participants were recruited through street-based outreach and snowball sampling.

Primary outcome measure: HCV antibody seroconversion, measured every 6 months during follow-up. Risk for seroconversion from injection of prescription opioids was compared with injection of other street drugs of misuse, including heroin, cocaine or crystal methamphetamine, using Cox proportional hazards regression controlling for age, gender and syringe sharing.

Results: Baseline HCV seropositivity was $10.6 \%$. Among 512 HCV-seronegative youth contributing 860.2 person-years of follow-up, $56(10.9 \%)$ seroconverted, resulting in an incidence density of 6.5/100 personyears. In bivariate analyses, prescription opioid injection (HR=3.48; $95 \% \mathrm{Cl} 1.57$ to 7.70 ) predicted HCV seroconversion. However, in multivariate modelling, only injection of heroin (adjusted $\mathrm{HR}=4.56$; $95 \% \mathrm{Cl} 2.39$ to 8.70 ), cocaine (adjusted $\mathrm{HR}=1.88$; $95 \% \mathrm{Cl} 1.00$ to 3.54 ) and crystal methamphetamine (adjusted HR=2.91; 95\% Cl 1.57 to 5.38) remained independently associated with HCV seroconversion, whereas injection of prescription opioids did not (adjusted HR=0.94; $95 \% \mathrm{Cl} 0.40$ to 2.21).

Conclusions: Although misuse of prescription opioids is on the rise, traditional street drugs still posed the greatest threat of HCV transmission in this setting. Nonetheless, the high prevalence and incidence of HCV among Canadian street youth underscore the need for evidence-based drug prevention, treatment and harm reduction interventions targeting this vulnerable population.

\section{Strengths and limitations of this study}

- A strength of this prospective cohort study is that it followed street youth, a marginalised and difficult-to-reach population with a high prevalence of injection drug use and blood-borne infection, including HIV and hepatitis C virus (HCV).

- An additional strength is that it is among the first studies to examine the association between injection of prescription opioids (including, eg, oxycodone and morphine) and acquisition of $\mathrm{HCV}$; it is not well understood how the risk for acquiring HCV from injecting prescription opioids compares to that from injection of more traditionally studied street drugs, such as heroin, cocaine and crystal methamphetamine.

- The study's findings demonstrate an elevated risk for HCV seroconversion in relation to heroin, cocaine and crystal methamphetamine injection, but not prescription opioid injection after adjustment for covariates; however, the relatively small number of youth injecting prescription opioids may have limited detection of marginal risk differences.

- Since youth in the study were recruited by snowball sampling, results are not obtained from a truly random sample, but characteristics of the cohort are comparable to those from studies of street youth conducted elsewhere.

- This study demonstrates novel findings that should prompt further study of risk for bloodborne infection among drug-injecting youth populations.

\section{INTRODUCTION}

Hepatitis C virus (HCV) infection is a leading cause of morbidity and mortality worldwide. $^{1-3}$ While the incidence of HCV may be decreasing in some age groups, infection rates appear to be increasing among adolescents and young adults. ${ }^{4}$ Street youth-that is, youth who spend all or part of their time working or living on the street ${ }^{5}{ }^{6}$-represent a marginalised and stigmatised population at 
elevated risk for HCV acquisition owing to a high prevalence of injection drug use. ${ }^{3} 78$

The emergence of elevated rates of HCV among street youth coincides with important changes in patterns of youth substance use. In recent years, misuse of prescription opioids such as morphine, oxycodone and hydrocodone has emerged as a public health emergency. ${ }^{9}$ Although injection of illicit drugs is known to place users at high risk of blood-borne infection, ${ }^{10}{ }^{11}$ the abundance of studies until now has focused on traditional street drugs, such as heroin and cocaine, rather than prescription opioids. ${ }^{12}$

This constitutes a serious gap in our understanding of HCV epidemiology given that, in many jurisdictions, overdose mortality attributed to prescription opioid use has surpassed that attributed to the use of heroin and cocaine combined. ${ }^{13}$ The prevalence of non-medical prescription opioid use is increasing in the general adolescent population, ${ }^{14}$ with approximately $8-10 \%$ of high school students in the USA reporting past-year use. ${ }^{15}$ Many prescription opioid formulations are readily injected, ${ }^{16} 17$ but despite their widespread availability, there is a paucity of epidemiological data examining this practice or its risk for disease transmission. ${ }^{18}$

At this time, it remains unclear whether heroin injectors and prescription opioid injectors represent overlapping or distinct subpopulations of injection drug users. ${ }^{19}$ There is evidence that some users follow a trajectory from initially using prescription opioids to ultimately using heroin, since in some settings heroin is less expensive and more potent and available. ${ }^{16}$ On the other hand, there may be a sizeable subgroup of users who inject prescription opioids to the exclusion of heroin and other drugs. ${ }^{20}$ Nonetheless, there is reason to believe that certain injection practices associated with heroin as compared with prescription opioids may place users at differential risk for infectious disease transmission. ${ }^{1720}$

Understanding how the injection of prescription opioids may place users at risk for acquiring HCV is imperative, given that injection drug users represent the population at greatest risk for HCV infection in North America, ${ }^{21}{ }^{22}$ and that mortality from $\mathrm{HCV}$ has increased to the extent that it recently surpassed that from HIV in the USA. ${ }^{2}$ We conducted the present study of HCV acquisition in Vancouver, Canada among a prospective cohort of street youth, a population including a high proportion of Aboriginal youth who may be at elevated risk for blood-borne infection. ${ }^{23}$ Our study objective was to examine the contribution of injection of prescription opioids and that of traditional street drugs of misuse to the risk for HCV seroconversion.

\section{METHODS}

The At-Risk Youth Study (ARYS) is a cohort of street-involved youth in Vancouver, Canada. ${ }^{24}$ Inclusion criteria for enrolment included age 14-26 years and use of an illicit drug other than marijuana during the month prior to enrolment. Recruitment relied on extensive daytime and night-time street-based outreach and snowball sampling, and was systematically conducted in the parks, streets and alleyways of Vancouver where street youth are known to congregate. Although no inclusion criterion explicitly required a minimum amount of time on the street to qualify for the study, in practice the streetbased recruitment resulted in a sample of youth who spent substantial time on the street, a large proportion of whom were homeless. ${ }^{25}$ Full study details were disclosed to participants and informed consent was obtained. At baseline and every 6 months thereafter, participants completed an interview and underwent HCV antibody testing. Participants were remunerated \$C20 per visit. Additionally, a \$C5 incentive was provided to youth 3 months after their baseline interview to return to the study site to update their contact information in an attempt to improve study follow-up.

We compared HCV prevalence at recruitment and subsequent $\mathrm{HCV}$ incidence among youth according to the recent (ie, during the preceding 6 months) injection of a prescription opioid and recent injection of heroin, cocaine and crystal methamphetamine. Prescription opioids were broadly defined to include morphine, oxycodone, hydromorphone, meperidine, fentanyl or methadone. The exact question used was, "In the last 6 months, when you were using, which of the following drugs did you inject and how often?", with possible answers including, "Less than once per month/One to three times per month/About once per week/Two or three times per week/At least daily". Using this question, each of the prescription opioids listed above was individually and sequentially probed. We also examined patterns of non-injection use of prescription opioids in the sample. All ARYS participants were included in the baseline HCV prevalence analyses. Participants who were HCV antibody negative at baseline and returned for $\geq 1$ follow-up visit were included in the incidence analyses.

We also examined an additional array of covariates including: gender, age (as a continuous variable), Aboriginal ancestry, high school education (having completed or currently enrolled in high school), selfreported gay/lesbian/bisexual orientation, recent homelessness, recent incarceration, recent sharing of injection syringes, recent inconsistent condom use (vaginal or anal penetrative sex without condom use $100 \%$ of the time) and recent sex work (having traded sex for money, drugs, shelter or gifts). In the baseline prevalence analysis, all participants were compared according to $\mathrm{HCV}$ serostatus through $\chi^{2}$ (for categorical variables) and Wilcoxon rank-sum tests (for continuous variables). Similar statistics were also calculated to compare drug-related behaviours between Aboriginal and non-Aboriginal youth. ${ }^{23}$

We then conducted the incidence analysis with the outcome of time to HCV seroconversion, limiting the sample to those who were HCV antibody negative at baseline and returned for $\geq 1$ follow-up visit. Youth with 
and without a history of injection drug use were first compared in univariate analyses to consider differences between these two subgroups. ${ }^{26}$ We subsequently used Kaplan-Meier methods to plot the cumulative incidence of HCV seroconversion as a function of time. All follow-up data were included, even if a participant had missed an intervening follow-up appointment.

We also used Cox proportional hazards regression to determine unadjusted and adjusted HR for HCV seroconversion for the range of drug use-related variables and other covariates listed above. An interaction term between heroin and prescription opioid injection was also tested. The time of seroconversion was estimated as the midpoint of the date of the last known seronegativity and of that of the first seropositivity. ${ }^{27-29}$ Independent variables were time-updated in regression models if they referred to non-fixed characteristics or behaviours in the preceding 6 months. In the event of differential follow-up duration among participants recruited earlier in the study period compared to later in the study period, we examined the prevalence of prescription opioid injection and heroin in the first 2 years of study and in the past 2 years of study to determine whether these behaviours were becoming more common with time. ${ }^{14}$ We also examined prevalence of cocaine and crystal methamphetamine over the course of the study.

We sought to directly compare the risk for HCV seroconversion from injection of heroin and other traditional drugs of misuse to that from injection of prescription opioids, ${ }^{1720}$ and created three multivariable models to do so. The first model included recent heroin injection but not recent prescription opioid injection; the second, recent prescription opioid injection but not recent heroin injection; and the third, recent heroin injection and recent prescription opioid injection. To adjust for potential confounders, age and gender were included in multivariable models as well as covariates significant at $p<0.05$ in the initial bivariate Cox regression analyses of time to HCV seroconversion. Finally, as a subanalysis, we restricted the sample to drug-injecting youth and examined bivariate associations between injection of prescription opioids, heroin, cocaine and crystal methamphetamine and HCV seroconversion. We also repeated the third multivariate model using this subsample.

Analyses were conducted with SAS V.9.1 (SAS Institute, Inc, Cary, North Carolina, USA). All $p$ values were twosided and tests were considered significant at $\mathrm{p}<0.05$. Adjustments were not made for multiple comparisons given that this was a single-outcome observational study.

\section{RESULTS}

From September 2005 to November 2011, 940 youth were recruited into the ARYS cohort and completed baseline HCV antibody testing. One hundred youth $(10.6 \%)$ were $\mathrm{HCV}$-seropositive at study enrolment. Table 1 shows baseline characteristics and recent (ie, in the 6 months preceding study enrolment) drug-related and sexual risk behaviours according to HCV serostatus. The cohort spent a median of $12 \mathrm{~h}$ on the street per day

Table 1 Baseline characteristics of 940 street youth, according to the hepatitis C virus (HCV) serostatus at study enrolment: At-Risk Youth Study (ARYS), Vancouver, British Columbia, 2005-2011

\begin{tabular}{|c|c|c|c|c|c|}
\hline \multirow[b]{2}{*}{ Characteristic } & \multirow{2}{*}{$\begin{array}{l}\text { Total }(\%) \\
(n=940)\end{array}$} & \multicolumn{2}{|c|}{ HCV seropositive } & \multirow[b]{2}{*}{ OR $(95 \% \mathrm{Cl})$} & \multirow[b]{2}{*}{ p Value } \\
\hline & & Yes (\%) (n=100) & No (\%) $(n=840)$ & & \\
\hline \multicolumn{6}{|l|}{ Sociodemographic factors } \\
\hline Male gender & $654(69.6)$ & $63(63.0)$ & $591(70.4)$ & $0.72(0.47$ to 1.11$)$ & 0.131 \\
\hline Mean age $(S D)^{\star}$ & $21.7(2.7)$ & $23.4(2.5)$ & $21.5(2.7)$ & 1.34 (1.23 to 1.47$)$ & $<0.001$ \\
\hline Aboriginal ancestry & $224(23.8)$ & $30(30.0)$ & $194(23.1)$ & $1.43(0.90$ to 2.25$)$ & 0.126 \\
\hline High school education $†$ & $415(64.8)$ & $35(35.0)$ & $380(45.2)$ & $0.65(0.42$ to 1.00$)$ & 0.051 \\
\hline Gay/lesbian/bisexual & $151(16.1)$ & $22(22.0)$ & $129(15.4)$ & 0.64 (0.39 to 1.07$)$ & 0.087 \\
\hline Recent homelessnessł & $348(37.0)$ & $54(54.0)$ & $294(35.0)$ & 2.18 (1.44 to 3.31$)$ & $<0.001$ \\
\hline Recent incarceration $\ddagger$ & $176(18.7)$ & $26(26.0)$ & $150(17.9)$ & $1.62(1.00$ to 2.61$)$ & 0.048 \\
\hline \multicolumn{6}{|l|}{ Substance use-related behaviours } \\
\hline Mean years injecting (SD)§ & $4.3(3.2)$ & $4.0(3.3)$ & $4.6(3.2)$ & 0.94 (0.82 to 1.07$)$ & 0.350 \\
\hline Non-injection prescription opioid use $\ddagger$ & $90(9.6)$ & $12(12.0)$ & $78(9.3)$ & $1.33(0.70$ to 2.54$)$ & 0.383 \\
\hline Prescription opioid injection $\ddagger$ & $64(6.8)$ & $28(28.0)$ & $36(4.3)$ & $8.69(5.01$ to 15.1$)$ & $<0.001$ \\
\hline Heroin injection $\ddagger$ & $191(20.3)$ & $66(66.0)$ & 125 (14.9) & $11.1(7.04$ to 17.5$)$ & $<0.001$ \\
\hline Cocaine injection $\ddagger$ & $93(9.9)$ & $31(31.0)$ & $62(7.4)$ & 5.54 (3.43 to 9.26$)$ & $<0.001$ \\
\hline Crystal methamphetamine injection $\ddagger$ & $154(16.4)$ & $50(50.0)$ & $104(12.4)$ & 7.08 (4.55 to 11.0$)$ & $<0.001$ \\
\hline Syringe sharing $\ddagger$ & $56(6.0)$ & $18(18.0)$ & $38(4.5)$ & 4.63 (2.53 to 8.48$)$ & $<0.001$ \\
\hline \multicolumn{6}{|l|}{ Sexual risk behaviours } \\
\hline Inconsistent condom use & $433(46.1)$ & $40(40.0)$ & $393(46.8)$ & 0.76 (0.50 to 1.16$)$ & 0.198 \\
\hline Sex work $\ddagger$ & $65(6.9)$ & $14(14.0)$ & $51(6.1)$ & 2.52 (1.34 to 4.74$)$ & 0.003 \\
\hline
\end{tabular}


(IQR 6-24 h). Aboriginal youth comprised 224 (23.8\%) of the sample. Aboriginal and non-Aboriginal youth did not differ with regard to recent non-injection prescription opioid use, recent injection of prescription opioids, heroin, cocaine or crystal methamphetamine or recent syringe sharing ( $p>0.05$ for all). As shown, baseline HCV seropositivity was associated with older age, recent homelessness, recent incarceration, recent injection of prescription opioids, heroin, cocaine and crystal methamphetamine, recent syringe sharing and recent sex work. Recent injection of prescription opioids and of heroin were correlated $(\mathrm{p}<0.05)$.

Of the 840 youth who were HCV antibody negative at baseline, $512(60.9 \%)$ had at least one follow-up visit and provided blood samples for HCV antibody testing. Among these 512 youth, $151(29.5 \%)$ were female and $135(67.2 \%)$ identified as Aboriginal. The mean age was 21.7 (SD 2.6) years. Compared with the 328 (29.1\%) participants who were HCV antibody negative at baseline and did not provide follow-up data, the 512 participants included in subsequent incidence analyses tended to be older $(p<0.05)$, but did not differ at baseline in terms of gender, Aboriginal ancestry, recent incarceration, recent sex work, recent injection of prescription opioids, heroin, cocaine or crystal methamphetamine or recent syringe sharing.

At study enrolment, $166(32.4 \%)$ of the 512 youth included in the incidence analysis reported prior drug injection. Compared with those who had not previously injected, those who had injected were more likely to be older $(p<0.05)$, but otherwise did not differ by gender, Aboriginal ancestry, recent incarceration or recent sex work. Of the 166 youth who had previously injected, 56 $(33.7 \%)$ reported recently having injected two or more drugs among prescription opioids, heroin, cocaine and crystal methamphetamine, and $11(6.6 \%)$ reported having injected three or more of these drugs.

During the follow-up period (median follow-up, 18.5 months; median number of follow-up visits after baseline visit, 2 visits; total follow-up, 860.2 person-years), there were $56(10.9 \%)$ HCV seroconversions, resulting in an incidence density of $6.5 / 100$ person-years. As might be expected, median follow-up was longer in the earlier years of study enrolment (22 months in the first 2 years of enrolment vs 17 months in the final 2 years; $\mathrm{p}<0.001)$. The median number of missed visits during follow-up was 1 visit. Individuals lost to follow-up were censored at the time of their last visit.

Over the study period, the prevalence of prescription opioid injection remained relatively unchanged $(4.2 \%$ of the entire sample in the first 2 years of enrolment vs $4.4 \%$ in the past 2 years) as did that of heroin injection $(13.5 \%$ vs $11.8 \%)$. Similarly, there was very little change in the prevalence of cocaine injection $(12.2 \%$ of the entire sample in the first 2 years of enrolment vs $10.0 \%$ in the past 2 years) and crystal methamphetamine injection $(18.0 \%$ vs $16.8 \%)$. At baseline, recent heroin injectors and recent prescription opioid injectors did not differ in terms of age (mean, 21.8 vs 22.3 years, respectively; $\mathrm{p}=0.524$ ), gender ( $65.5 \%$ vs $72.2 \%$ male; $\mathrm{p}=0.202$ ), ethnicity (20.7\% Aboriginal vs $16.7 \%$ other; $\mathrm{p}=0.256$ ), age of initiation of injection drug use (mean, 17.7 vs 18.7 years; $\mathrm{p}=0.271$ ) or in total number of years of injecting (mean, 4.1 vs 3.6 years; $p=0.567$ ).

Figure 1A shows the Kaplan-Meier cumulative incidence of HCV seroconversion according to heroin injection in the entire sample and figure $1 \mathrm{~B}$ shows the cumulative incidence according to heroin injection with the sample restricted to drug-injecting youth only. In both cases, heroin injectors had a markedly elevated risk of HCV seroconversion in comparison to others in the sample, including prescription opioid injectors (full data available from the corresponding author). The crude incidence density of HCV seroconversion among heroin-injecting youth was 20.8/100 person-years, and among prescription opioid-injecting youth it was 21.4/ 100 person-years. The mean number of visits prior to seroconversion did not differ between heroin and prescription opioid injectors $(\mathrm{p}>0.05)$.

Table 2 displays the results of the unadjusted and adjusted Cox proportional hazard regression analyses of the time to detected HCV seroconversion according to demographic characteristics and risk behaviours. As shown, HCV seroconversion was significantly associated with female gender, prescription opioid injection, heroin injection, cocaine injection, crystal methamphetamine injection and syringe sharing in unadjusted analyses. Age was not associated with HCV seroconversion. Additional variables not listed in the table that were not significantly associated with HCV seroconversion included Aboriginal ancestry (unadjusted $\mathrm{HR}=0.88$; $95 \%$ CI 0.49 to $1.59 ; \mathrm{p}=0.662$ ), recent incarceration $(\mathrm{HR}=1.25 ; 95 \%$ CI 0.67 to $2.32 ; \mathrm{p}=0.482)$, recent inconsistent condom use (unadjusted $\mathrm{HR}=0.90 ; 95 \%$ CI 0.52 to $1.55 ; \mathrm{p}=0.703$ ) and recent sex work (unadjusted $\mathrm{HR}=0.91 ; 95 \%$ CI 0.28 to $2.90 ; \mathrm{p}=0.869$ ). Additionally, the interaction term between heroin and prescription opioid injection was not significant $(p>0.05)$.

The three multivariable models examining the relative effects of prescription opioid injection and heroin injection all were adjusted for gender and age, as well as for variables significant at $\mathrm{p}<0.05$ in unadjusted Cox regression analyses (cocaine injection, crystal methamphetamine injection and syringe sharing). In the model including all covariates except prescription opioid injection, heroin injection remained significantly associated with HCV seroconversion (model 1), whereas prescription opioid injection did not retain significance in the model including all covariates except heroin (model 2). When heroin injection and prescription opioid injection were included, a combined model, heroin injection, but not prescription opioid injection, retained statistical significance (model 3).

When the sample was restricted to only drug-injecting youth $(n=166)$, prescription opioid injection was not associated with HCV seroconversion in bivariate analyses 


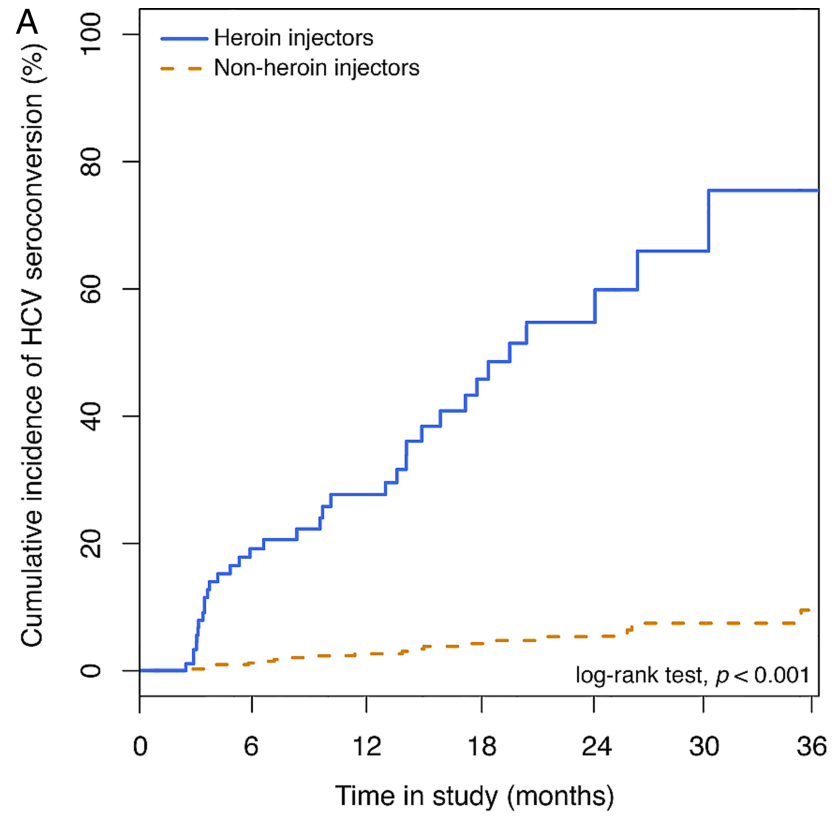

B

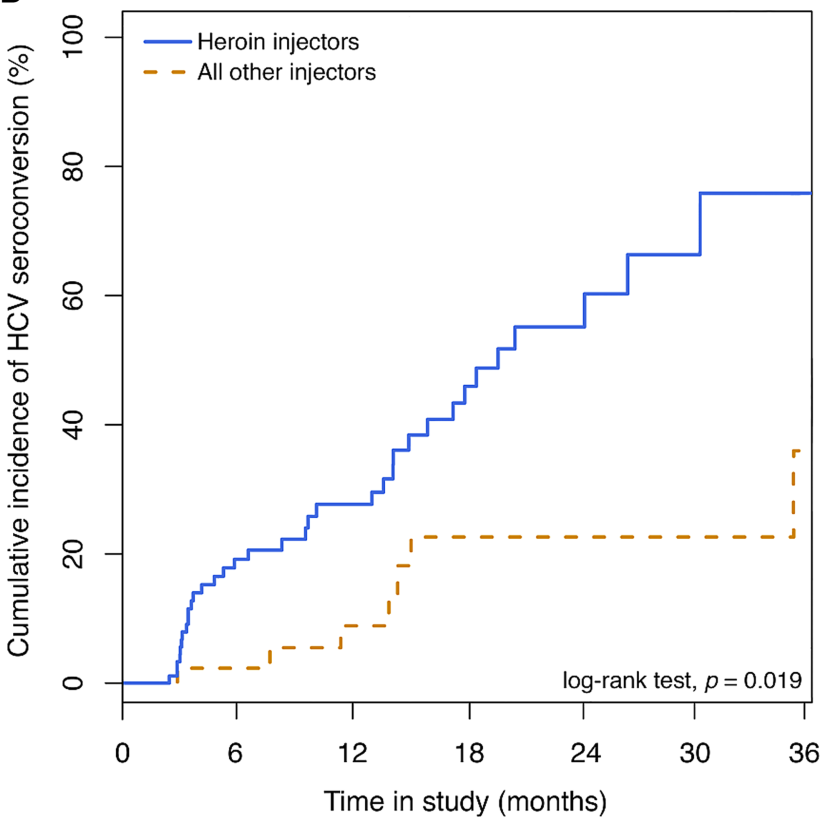

Figure 1 (A) Cumulative incidence of hepatitis $C$ infection among (A) 512 drug-using youth, by injection heroin use and (B) drug-injecting youth by heroin use: At-Risk Youth Study (ARYS), Vancouver, Canada, 2005-2010.

(unadjusted $\mathrm{HR}=1.27 ; 95 \%$ CI 0.57 to 2.84; $\mathrm{p}=0.555$ ). Heroin injection was associated with HCV seroconversion in this subsample (unadjusted $\mathrm{HR}=2.93 ; 95 \%$ CI 1.77 to $6.13 ; \mathrm{p}<0.001)$, as was cocaine injection (unadjusted $\mathrm{HR}=2.02 ; 95 \%$ CI 1.11 to $3.68 ; \mathrm{p}=0.021$ ), but not crystal methamphetamine injection (unadjusted $\mathrm{HR}=4.52 ; 95 \%$ CI 0.61 to $33.3 ; \mathrm{p}=0.136$ ). Syringe sharing was also associated with $\mathrm{HCV}$ seroconversion (unadjusted HR=2.93; 95\% CI 1.48 to 5.79; $\mathrm{p}=0.002$ ). When model 3 was rerun using this subsample, variables remaining significantly associated with HCV seroconversion included heroin injection (adjusted HR=2.79; 95\%
CI 1.46 to 5.34; $\mathrm{p}=0.002$ ) and syringe sharing (adjusted $\mathrm{HR}=2.47$; 95\% CI 1.22 to 4.98 ; $\mathrm{p}=0.012$ ), but not prescription opioid injection (adjusted HR $=0.60 ; 95 \%$ CI 0.25 to $1.47 ; \mathrm{p}=0.268$ ), cocaine injection (adjusted $\mathrm{HR}=1.83 ; 95 \%$ CI 0.98 to $3.40 ; \mathrm{p}=0.057$ ) or crystal methamphetamine injection (adjusted $\mathrm{HR}=4.13 ; 95 \%$ CI 0.47 to $36.0 ; \mathrm{p}=0.199$ ).

\section{DISCUSSION}

In this longitudinal study, we observed a high prevalence of HCV seropositivity among adolescents and young adults on the street, with more than 1 in 10 youth infected with HCV at baseline, as well as high incidence HCV acquisition during follow-up. We observed that injections of heroin, cocaine and crystal methamphetamine were all strongly associated with risk HCV seroconversion following adjustment for potential confounders. Injection of prescription opioids, in contrast, was not independently associated with HCV seroconversion in adjusted models, although it was associated with HCV seropositivity at baseline and with HCV seroconversion in unadjusted analyses. Taken together, these findings highlight street youth as a population that should remain a critical focus for evidence-based drug preventive and treatment services to prevent a worsening HCV epidemic.

Although misuse of prescription opioids is on the rise in North America, ${ }^{15}$ and although they are readily injected, ${ }^{16}{ }^{17}$ we did not observe excess risk for HCV seroconversion from injection of prescription opioids among Vancouver street youth after controlling for other factors. There are several plausible explanations for the null finding in this setting. First, we acknowledge that despite a large sample of drug-using youth, the proportion of participants in the cohort who engaged in prescription opioid injection was relatively small and may have somewhat limited detection of marginal risk differences. Prescription opioid injection was significantly associated with HCV seroconversion in univariate incidence analyses, suggesting increased risk from this behaviour. However, in the setting of polysubstance use, which was common in this setting, the contribution of prescription opioid injection to risk for HCV seroconversion appears to be relatively less important than that of traditional drugs of misuse including heroin, cocaine and crystal methamphetamine. Indeed, since injections of prescription opioids and of heroin were correlated in our sample, our results are consistent with those of other reports that many heroin injectors also inject prescription opioids when they cannot easily locate heroin or cannot afford it. ${ }^{17}$ We recommend that future studies actively recruit prescription opioid-injecting youth in order to improve estimates of risk for HCV.

Second, as has been described elsewhere, populations of drug users often show great heterogeneity, with subpopulations exhibiting widely varying risk for bloodborne disease. ${ }^{19}$ In Vancouver, youth who inject 
Table 2 Unadjusted and adjusted Cox proportional hazard analysis of time to hepatitis C infection among 512 drug-using youth: At-Risk Youth Study (ARYS), Vancouver, British Columbia, 2005-2011

\begin{tabular}{|c|c|c|c|c|}
\hline \multirow[b]{2}{*}{ Characteristic } & \multirow[b]{2}{*}{ Unadjusted HR (95\% Cl) } & \multicolumn{3}{|c|}{ Adjusted HR (95\% Cl) } \\
\hline & & Model 1* & Model 2† & Model 3‡ \\
\hline Male gender & $0.48(0.28$ to 0.81$)$ & 0.50 (0.28 to 0.90$)$ & $0.42(0.24$ to 0.75$)$ & 0.50 (0.28 to 0.90$)$ \\
\hline Age (per year older) & $0.96(0.87$ to 1.06$)$ & $1.10(0.91$ to 1.10$)$ & $1.00(0.91$ to 1.11$)$ & $1.00(0.91$ to 1.10$)$ \\
\hline Prescription opioid injection & 3.48 (1.57 to 7.70$)$ & - & $2.02(0.89$ to 4.61$)$ & 0.94 (0.40 to 2.21$)$ \\
\hline Heroin injection & 9.89 (5.72 to 17.1$)$ & 4.49 (2.42 to 8.33$)$ & - & 4.56 (2.39 to 8.70$)$ \\
\hline Cocaine injection & 5.69 (3.18 to 10.2$)$ & 1.87 (1.00 to 3.47$)$ & 2.20 (1.14 to 4.23$)$ & 1.88 (1.00 to 3.54$)$ \\
\hline Crystal methamphetamine injection & 7.39 (4.36 to 12.5$)$ & 2.94 (1.62 to 5.34$)$ & 5.11 (2.79 to 9.34$)$ & 2.91 (1.57 to 5.38$)$ \\
\hline Syringe sharing & 7.69 (3.93 to 15.0$)$ & 2.47 (1.20 to 5.09$)$ & 2.57 (1.24 to 5.32$)$ & 2.47 (1.20 to 5.10$)$ \\
\hline
\end{tabular}

*Model 1 includes all covariates listed except prescription opioid injection.

†Model 2 includes all covariates listed except heroin injection.

$\ddagger$ Model 3 includes all covariates listed.

prescription opioids, regardless of whether they also inject other drugs, may represent a distinct subpopulation from other higher risk youth who inject heroin, cocaine or crystal methamphetamine but not prescription opioids, as has been observed in other settings. ${ }^{20} \mathrm{It}$ is possible that prescription opioid-injecting youth may not be as entrenched in the local drug scene ${ }^{30}$ and, as a result, may not associate as frequently with HCV-seropositive drug users. Similarly, youth who inject prescription opioids may have received different preventive messaging regarding safe injection practices, or have better access to harm reduction services. A better understanding of the risk environment for prescription opioid users will prove important for preventing transmission of $\mathrm{HCV}$ in this high-risk population.

Although prescription opioid injection was not independently associated with risk for HCV seroconversion, more traditional risk factors, including injection of heroin, cocaine, and crystal methamphetamine, were strongly and independently associated with HCV acquisition in this setting. These findings are consistent with those from previous youth studies. ${ }^{8}{ }^{31-33}$ It is well established that HCV is spread when drug users share injection paraphernalia. ${ }^{34}{ }^{35}$ Interestingly, although syringe sharing was associated with HCV seroconversion in the ARYS sample, it did not fully explain the risk for HCV associated with injection of heroin, cocaine and crystal methamphetamine in final multivariable models. A possible explanation may be that youth under-reported syringe sharing, which might be perceived as a stigmatised behaviour. The result of such socially desirable reporting could be the incomplete effect sizes observed in our statistical models. ${ }^{36} 37$ Nonetheless, attempts to prevent the spread of HCV among at-risk youth will require careful attention to factors that interfere with safe injection practices, including peer dynamics and chaotic injection environments. $^{38} 39$

The excess risk for HCV among street youth necessitates evidence-based strategies to prevent drug use and mitigate injection-related harm. Although maintenance therapy with methadone or buprenorphine is efficacious among adolescents and young adults, ${ }^{40}$ challenges remain in making these services accessible to street youth, who are a marginalised and difficult-to-reach population. ${ }^{42}{ }^{43}$ Other effective harm reduction services such as needle exchange and supervised safe injection facilities are often developed for adult drug users and may not effectively target younger drug users. ${ }^{3}$ Barriers to preventive and treatment modalities for young drug users are well documented, and include excessively long waiting lists, difficulty in complying with programme rules, programme fees that exceed young people's ability to pay, and locations that are inconvenient for youth. ${ }^{42}$ Existing drug treatment and harm reduction services should be extended in a way that is sensitive to the unique circumstances of youth.

There are limitations to this study. First, as outlined above, we acknowledge a relatively small proportion of the sample who injected prescription opioids, which may have affected the precision of our estimates. Second, we employed snowball sampling in order to recruit heavily drug-involved youth, who are frequently homeless and represent a population 'hidden' from traditional population-based sampling. Although snowball sampling does not produce a truly random sample,${ }^{24}$ it is noteworthy that the characteristics of the ARYS cohort are similar to those of other at-risk youth in western Canada. ${ }^{44}{ }^{45} \mathrm{~A}$ final point regarding representativeness is the refusal rate among youth who are approached for enrolment into the study. Unfortunately, as youth often self-refer and street-based outreach often requires a very low threshold approach commonly involving repeated contact, rates of refusal can only be estimated. Study staff estimate that $30 \%$ of youth first approached for participation ultimately agree to be assessed for eligibility. Third, our study relied on selfreport, which, as outlined above, may have resulted in social desirability bias for questions probing sensitive details. Finally, for polysubstance-using youth in the sample, we cannot rule out that the risk for HCV in our models attributed to heroin may have been better attributed to risky behaviours associated with injection of other drugs. However, we sought to explore the independent effects of other drugs in our modelling by 
controlling for injection of the most common of other substances of misuse.

In summary, we found that the risk for HCV acquisition among street youth in this setting was alarmingly high, and that intravenous drug injection remains a primary risk factor. Interestingly, although prescription opioid misuse is on the rise in North America, in our sample, the risk of HCV acquisition from injection of prescription opioids did not exceed that of traditional street drugs, including heroin, cocaine and crystal methamphetamine. Nonetheless, prescription opioid injection should be the focus of further study to explore this emerging and poorly understood practice. Given the high prevalence and incidence of HCV seropositivity among street youth, there is an urgent need for evidence-based strategies, including educational programming, addiction treatment and harm reduction services, to prevent disease transmission in this vulnerable population.

\section{Author affiliations}

${ }^{1}$ Division of Adolescent \& Young Adult Medicine, Department of Medicine, Boston Children's Hospital, Boston, Massachusetts, USA

${ }^{2}$ Department of Pediatrics, Harvard Medical School, Boston, Massachusetts, USA

${ }^{3}$ British Columbia Centre for Excellence in HIV/AIDS, St. Paul's Hospital, Vancouver, British Columbia, Canada

${ }^{4}$ School of Population and Public Health, University of British Columbia, Vancouver, British Columbia, Canada

${ }^{5}$ Faculty of Medicine, University of British Columbia, Vancouver, British Columbia, Canada

${ }^{6}$ University of Saskatchewan, School of Public Health, Saskatoon,

Saskatchewan, Canada

Acknowledgements The authors thank the study participants for their contribution to the research, as well as current and past researchers and staff. The authors also specifically thank Deborah Graham, Peter Vann, Caitlin Johnston, Steve Kain and Calvin Lai for their research and administrative assistance. They also appreciate support from Dr Bob Vinci and the Boston Combined Residency Program, as well as Dr Jean Emans and the Division of Adolescent/Young Adult Medicine at Boston Children's Hospital. The corresponding author affirms that all who contributed significantly to the work are acknowledged

Contributors SEH, KDB, TK and EW designed the study. SEH, KDB and EW wrote the protocol. SEH conducted the literature review and wrote the first draft of the manuscript. CF undertook statistical analyses with additional input from SEH. All authors contributed to and have approved the final manuscript.

Funding This work was supported by the US National Institutes of Health (grant number R01DA028532); the Canadian Institutes of Health Research (grant number MOP-102742); the Canada Research Chairs (Tier 1 Canada Research Chair in Inner City Medicine, EW); Maternal Child Health Bureau of the Health Services Research Administration (Leadership Education in Adolescent Health, grant number T71 MC00009, SEH.); and National Institute of Drug Abuse, USA National Institutes of Health (Avant-Garde award, grant number DP1DA026182, J. SM).

Competing interests JSM has received educational grants from, served as an ad hoc advisor to or spoken at various events sponsored by Abbott Laboratories, Agouron Pharmaceuticals Inc, Boehringer Ingelheim Pharmaceuticals Inc, Borean Pharma AS, Bristol-Myers Squibb, DuPont Pharma, Gilead Sciences, GlaxoSmithKline, Hoffmann-La Roche, Immune Response Corporation, Incyte, Janssen-Ortho Inc, Kucera Pharmaceutical Company, Merck Frosst Laboratories, Pfizer Canada Inc, Sanofi Pasteur, Shire Biochem Inc, Tibotec Pharmaceuticals Ltd. and Trimeris Inc.
Ethics approval ARYS was approved by the University of British Columbia/ Providence Health Care Research Ethics Board.

Provenance and peer review Not commissioned; externally peer reviewed.

Data sharing statement Statistical code and data maintained by the corresponding author at the British Columbia Centre for Excellence in HIV/ AIDS. The Centre provides a permanent home for the data set. The corresponding author had full access to all the data in the study and takes responsibility for the integrity of the data and the accuracy of the data analysis. Data are available by emailing the Corresponding Author at uhri-ew@cfenet.ubc.ca

Open Access This is an Open Access article distributed in accordance with the Creative Commons Attribution Non Commercial (CC BY-NC 4.0) license, which permits others to distribute, remix, adapt, build upon this work noncommercially, and license their derivative works on different terms, provided the original work is properly cited and the use is non-commercial. See: http:// creativecommons.org/licenses/by-nc/4.0/

\section{REFERENCES}

1. Lavanchy D. The global burden of hepatitis C. Liver Int 2009;29 (Suppl 1):74-81.

2. Ly KN, Xing J, Klevens RM, et al. The increasing burden of mortality from viral hepatitis in the United States between 1999 and 2007. Ann Intern Med 2012;156:271-8.

3. Miller CL, Spittal PM, Frankish JC, et al. HIV and hepatitis C outbreaks among high-risk youth in Vancouver demands a public health response. Can J Public Health 2005;96:107-8.

4. Centers for Disease Control and Prevention (CDC). Hepatitis $C$ virus infection among adolescents and young adults:Massachusetts, 2002-2009. MMWR Morb Mortal Wkly Rep 2011;60:537-41.

5. The State of the World's Children 1997. 1997. http://www.unicef.org/ sowc97/download.htm (accessed 10 Jul 2009).

6. Street youth in Canada: findings from the enhanced surveillance of Canadian street youth, 1999-2003. 2006. http://www.phac-aspc.gc ca/std-mts/reports_06/pdf/street_youth_e.pdf (accessed 16 Jun 2009).

7. Hadland SE, Werb D, Kerr T, et al. Childhood sexual abuse and risk for initiating injection drug use: a prospective cohort study. Prev Med 2012;55:500-4.

8. Roy $\mathrm{E}$, Haley N, Leclerc $\mathrm{P}$, et al. Risk factors for hepatitis $\mathrm{C}$ virus infection among street youths. CMAJ 2001;165:557-60.

9. CDC. Vital signs: overdoses of prescription opioid pain relieversUnited States, 1999-2008. MMWR Morb Mortal Wkly Rep 2011;60:1487-92.

10. Des Jarlais DC, Friedman SR. HIV infection among intravenous drug users: epidemiology and risk reduction. AIDS 1987;1:67-76.

11. Garfein RS, Vlahov D, Galai N, et al. Viral infections in short-term injection drug users: the prevalence of the hepatitis $C$, hepatitis $B$, human immunodeficiency, and human T-lymphotropic viruses. Am J Public Health 1996;86:655-61.

12. Degenhardt L, Hall W. Extent of illicit drug use and dependence, and their contribution to the global burden of disease. Lancet 2012;379:55-70.

13. Highlights of the 2009 Drug Abuse Warning Network (DAWN) Findings on Drug-Related Emergency Department Visits. 2010. http://www.samhsa.gov/data/2k10/dawnsr034edhighlights/ edhighlights.htm (accessed 20 Feb 2012)

14. Miech R, Bohnert A, Heard K, et al. Increasing use of nonmedical analgesics among younger cohorts in the United States: a birth cohort effect. J Adolesc Health 2013;52:35-41.

15. Results from the 2012 National Survey on Drug Use and Health: Summary of National Findings. 2013. http://www.samhsa.gov/data/ NSDUH/2012SummNatFindDetTables/NationalFindings/ NSDUHresults2012.htm (accessed 30 Dec 2013).

16. Lankenau SE, Teti M, Silva K, et al. Initiation into prescription opioid misuse amongst young injection drug users. Int J Drug Policy 2012;23:37-44.

17. Roy E, Arruda N, Bourgois $\mathrm{P}$. The growing popularity of prescription opioid injection in downtown Montreal: new challenges for harm reduction. Subst Use Misuse 2011;46:1142-50.

18. Fischer B, Rehm J, Patra J, et al. Changes in illicit opioid use across Canada. CMAJ 2006;175:1385.

19. Shaw SY, Shah L, Jolly AM, et al. Identifying heterogeneity among injection drug users: a cluster analysis approach. Am J Public Health 2008;98:1430-7. 
20. Bruneau J, Roy E, Arruda N, et al. The rising prevalence of prescription opioid injection and its association with hepatitis $\mathrm{C}$ incidence among street-drug users. Addiction 2012;107:1318-27.

21. Daniels D, Grytdal S, Wasley A; Centers for Disease C, Prevention. Surveillance for acute viral hepatitis-United States, 2007. MMWR Surveill Summ 2009:58:1-27.

22. Zou S, Tepper M, Giulivi A. Current status of hepatitis C in Canada. Can J Public Health 2000;91(Suppl 1):S10-15, S10-16.

23. Wood E, Montaner JS, Li K, et al. Burden of HIV infection among aboriginal injection drug users in Vancouver, British Columbia. Am J Public Health 2008;98:515-19.

24. Wood E, Stoltz JA, Montaner JSG, et al. Evaluating methamphetamine use and risks of injection initiation among street youth: the ARYS study. Harm Reduct J 2006;3:18.

25. Marshall BD, Kerr T, Shoveller JA, et al. Homelessness and unstable housing associated with an increased risk of HIV and STI transmission among street-involved youth. Health Place 2009;15:753-60.

26. Hadland SE, Kerr T, Marshall BD, et al. Non-injection drug use patterns and history of injection among street youth. Eur Addict Res 2010;16:91-8

27. Hagan $\mathrm{H}$, Thiede $\mathrm{H}$, Des Jarlais DC. Hepatitis $\mathrm{C}$ virus infection among injection drug users: survival analysis of time to seroconversion. Epidemiology 2004;15:543-9.

28. Hahn JA, Page-Shafer K, Lum PJ, et al. Hepatitis C virus seroconversion among young injection drug users: relationships and risks. J Infect Dis 2002;186:1558-64.

29. Shannon K, Kerr T, Marshall B, et al. Survival sex work involvement as a primary risk factor for hepatitis $C$ virus acquisition in drug-using youths in a canadian setting. Arch Pediatr Adolesc Med 2010;164:61-5.

30. Fast D, Small W, Wood E, et al. Coming 'down here': Young people's reflections on becoming entrenched in a local drug scene. Soc Sci Med 2009;21:21.

31. Garfein RS, Doherty MC, Monterroso ER, et al. Prevalence and incidence of hepatitis $\mathrm{C}$ virus infection among young adult injection drug users. J Acquir Immune Defic Syndr Hum Retrovirol 1998;18 (Suppl 1):S11-19.

32. Miller CL, Johnston C, Spittal PM, et al. Opportunities for prevention: hepatitis $C$ prevalence and incidence in a cohort of young injection drug users. Hepatology 2002;36:737-42.
33. Miller CL, Kerr T, Fischer B, et al. Methamphetamine injection independently predicts hepatitis $\mathrm{C}$ infection among street-involved youth in a Canadian setting. J Adolesc Health 2009;44:302-4.

34. Hagan $\mathrm{H}$, Pouget ER, Williams IT, et al. Attribution of hepatitis $\mathrm{C}$ virus seroconversion risk in young injection drug users in 5 US cities. J Infect Dis 2010;201:378-85.

35. Thorpe LE, Ouellet LJ, Hershow R, et al. Risk of hepatitis C virus infection among young adult injection drug users who share injection equipment. Am J Epidemiol 2002;155:645-53.

36. Fennema JS, van Ameijden EJ, Coutinho RA, et al. Validity of self-reported sexually transmitted diseases in a cohort of drug-using prostitutes in Amsterdam: trends from 1986 to 1992. Int J Epidemiol 1995;24:1034-41.

37. Koester S, Heimer R, Baron AE, et al. Re: 'Risk of hepatitis C virus among young adult injection drug users who share injection equipment'. Am J Epidemiol 2003;157:376; author reply 376-378.

38. Marshall BD, Kerr T, Qi J, et al. Public injecting and HIV risk behaviour among street-involved youth. Drug Alcohol Depend 2010;110:254-8.

39. Racz J, Gyarmathy VA, Neaigus A, et al. Injecting equipment sharing and perception of HIV and hepatitis risk among injecting drug users in Budapest. AIDS Care 2007;19:59-66.

40. Kimber J, Copeland L, Hickman M, et al. Survival and cessation in injecting drug users: prospective observational study of outcomes and effect of opiate substitution treatment. BMJ 2010;341:c3172.

41. Woody GE, Poole SA, Subramaniam G, et al. Extended vs short-term buprenorphine-naloxone for treatment of opioid-addicted youth: a randomized trial. JAMA 2008;300:2003-11.

42. Hadland SE, Kerr T, Li K, et al. Access to drug and alcohol treatment among a cohort of street-involved youth. Drug Alcohol Depend 2009;101:1-7.

43. Miller CL, Strathdee SA, Li K, et al. A longitudinal investigation into excess risk for blood-borne infection among young injection drug users (IUDs). Am J Drug Alcohol Abuse 2007;33:527-36.

44. Miller CL, Strathdee SA, Kerr T, et al. Factors associated with early adolescent initiation into injection drug use: implications for intervention programs. J Adolesc Health 2006;38:462-4.

45. Ochnio JJ, Patrick D, Ho M, et al. Past infection with hepatitis A virus among Vancouver street youth, injection drug users and men who have sex with men: implications for vaccination programs. CMAJ 2001:165:293-7. 